\title{
FAMILY FRAMING AND THE COMEDY OF CONVENTIONS IN RUBEN ÖSTLUND'S FORCE MAJEURE
}

\section{Roger Edholm}

\begin{abstract}
Ruben Östlund's Force Majeure (2014) centres around a Swedish family vacationing at a ski resort in the Alps. The film depicts how the family breaks down after the father leaves his wife and children behind while fleeing from a possible avalanche. This breakdown is reflected in the film's use of framing. In the opening scenes, the viewer is presented with a series of family portraits. After the averted disaster, the family is no longer shown as a coherent whole. Framing in Force Majeure is thus as a technical as well as a thematic matter related to the film's exploration of the nuclear family. Framing is also connected to the comedic characterization of the family that the film depicts. Rather than identifying with them, the viewer is invited to critically reflect upon their self-image and their actions. The focus of this essay is therefore the concept of framing in connection with the film's theme of family and certain comedic conventions. Force Majeure is symmetrically structured and the narrative progression adheres to a traditional plot-pattern moving from the disruption of order to the restoration of order. Yet, the film also flaunts its structure and makes the viewer aware of the clichés of conventional storytelling as these clichés and conventions are reproduced in the lives of the main characters.
\end{abstract}

\section{KEYWORDS}

Force Majeure, Framing, Family, Comedy, Conventions, Nature, Camera

\section{INTRODUCTION}

Ruben Östlund's fourth feature film Force Majeure (2014) begins with the making of a family portrait. The film crosscuts between the opening credits and a shot of an alpine landscape. Before the first frame of the film, we hear voices. A tourist photographer is persuading a Swedish family on vacation to pose for a picture. As the first shot appears, we can see the photographer summoning the family, all dressed in ski clothes, into the frame while he himself moves out of the frame, taking his place behind the camera. The image is interspersed with the opening credits again, and when the 
family returns on-screen, we see them posing for the camera while the photographer gives them instructions.

This opening scene can be interpreted as an establishing shot in several regards. The scene establishes some of the central themes in Force Majeure, which concern among other things the construction of the nuclear family as a natural and coherent unity. The framing of this static shot also establishes a sense of the film's visual style, and the awkwardness of the situation is characteristic of the comedic and ironic distance through which the director chooses to present his characters. The scene thus creates a particular viewer position in which we are made conscious of the constructedness of this family portrait. The photographer outside the frame directs the characters and the metafictional aspect of this conceit makes the viewers aware that they are watching people pretending to be a family - or at least trying to present themselves as a family according to clichéd and stereotyped images of family life.

Marianne Hirsch argues that "photography's social functions are integrally tied to the ideology of the modern family" and that the "family photo both displays the cohesion of the family and is an instrument of its togetherness...." ${ }^{1}$ Hirsch states that because "the photograph gives the illusion of being a simple transcription of the real, a trace touched directly by the event it records, it has the effect of naturalizing cultural practices and of disguising their stereotyped and coded characteristics." 2 In the opening of Force Majeure, the viewer is invited to critically approach the constructedness of the family photo and to see what the family photograph usually disguises. The viewer watches the process of making the family image while the characters in the film are concerned with photography as a display of the cohesion of the family and as an expression of togetherness, as we see when the mother, Ebba, looks at prints of the photographs a few minutes into the film.

It is possible to argue that the opening of the film, by using the tourist photographer to direct the characters on-screen, employs a Brechtian device in order for the viewer to apply a critical distance towards the family being portrayed. Rather than identifying with them, the viewer is invited to critically reflect upon their self-image and actions, but also, quite simply, to laugh at their behaviour. The film in fact works as a comedy and this essay will in part discuss the film in connection with comedic conventions and traditions. The focus of the essay is the use of framing in connection with the comedic characterization of the family that the film depicts. By analysing the opening shots of the film, it becomes notable that framing in Force Majeure is a technical as well as a thematic matter 

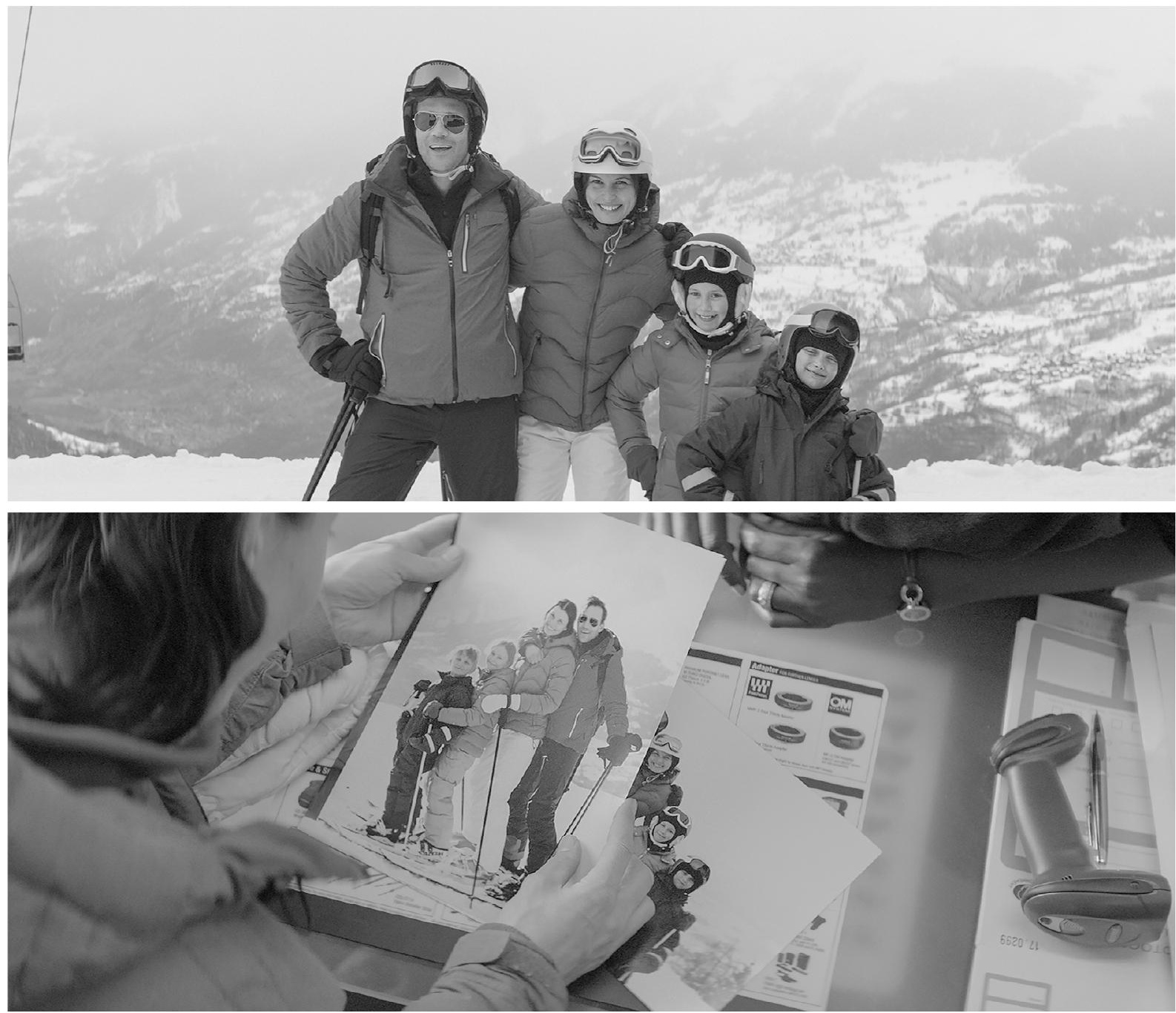

(Force Majeure, 0.01.44)

(Force Majeure, 0.06.02) 
related to the film's exploration of the nuclear family. The film is concerned with how to present the family, yet at the same time examine the ways in which the family aims to present itself.

In comparison to Östlund's previous three feature films - The Guitar Mongoloid (2004), Involuntary (2008), and Play (2011) Force Majeure is more conventional regarding narrative structure and the depiction of characters, as I argue in this essay, yet its formal aspects are inseparable from how the film explores conventions, roles, and stereotypes within the family being depicted. Force Majeure is symmetrically structured and the narrative progression adheres to a traditional plot-pattern moving from the disruption of order - in this case, the order within the family, the order between man and wife, the order between man and nature, and so on - to the restoration of order. The film also flaunts its structure and makes the viewer aware of the clichés of conventional storytelling as these clichés and conventions are reproduced in the lives of the main characters.

\section{A CRISIS OF INTERPRETATION: INSIDE THE FAMILY FRAME}

At the beginning of the film, during the "First Ski-Day," the family in Force Majeure is presented through a series of family portraits. After the avalanche scene, when Tomas, the father, abandons his family at a restaurant table and flees from the catastrophe on his own, the family is no longer situated within the same frame and in the same manner. In the avalanche scene, Tomas literally runs out of the frame, leaving his family behind and then returns as if nothing has happened. In what follows in the film, it becomes apparent that the family frame has been disrupted. The shots from the beginning, where the family is depicted together symmetrically within the composition of the shot, are replaced by medium shots and closeups to indicate that the family is no longer a coherent whole. When the family members are together within the same frame, they are now separated by the distance between the background and the foreground, or by certain objects, for example doors. In one shot, when the family has returned to the hotel room and the children wish to be left alone in the parent's bedroom, only the children's faces and bodies are seen in the shot. The camera is positioned at a low angle and only parts of the parents are visible within the frame, mainly their legs, and the shot can be contrasted with the earlier image of the family sleeping together on the bed.

The disrupted order within the family is thus reflected in the framing of shots, and the use of framing is connected to the representation of family. Therefore, the concept of frame is not 

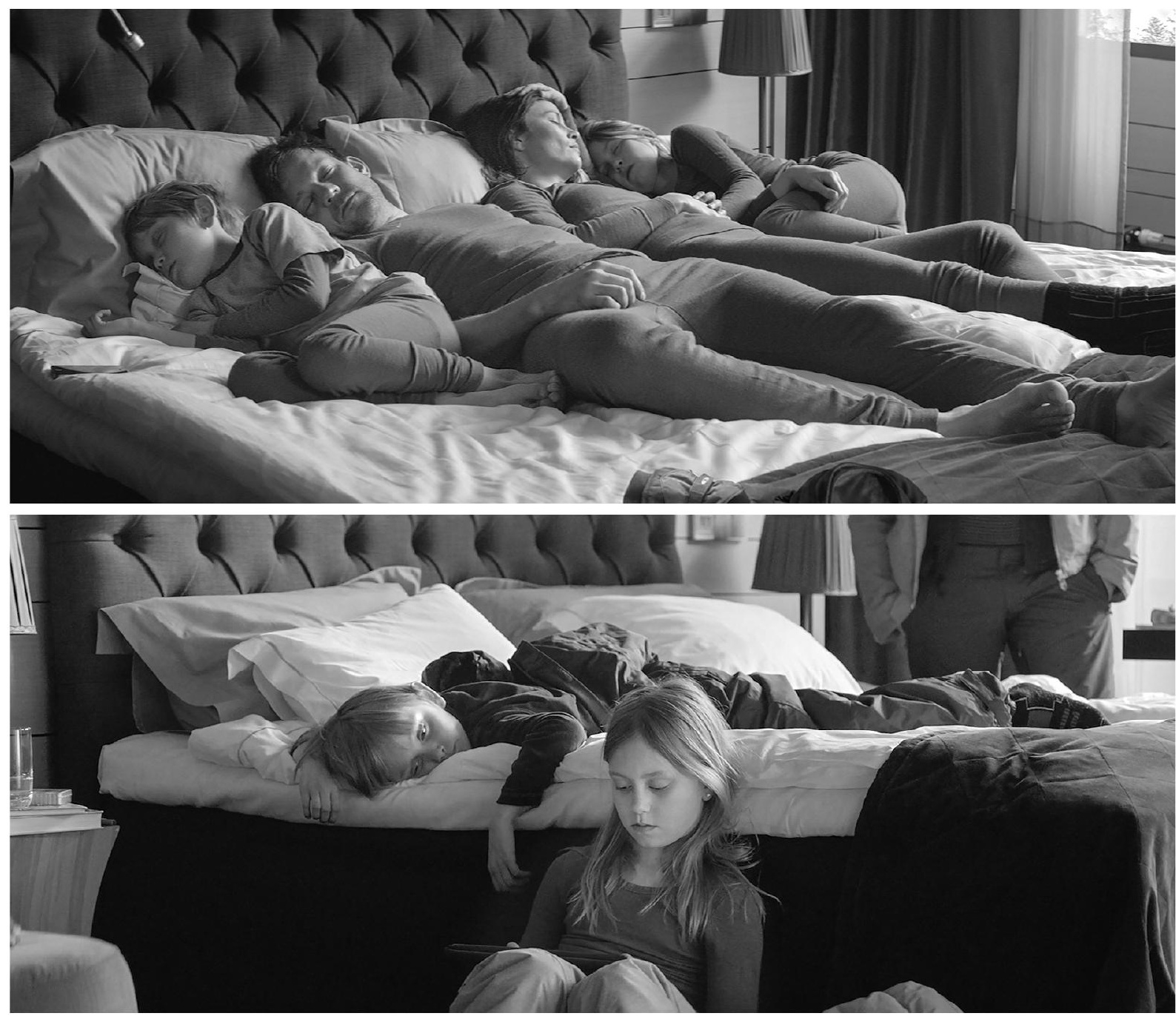

(Force Majeure, 0.08.25)

(Force Majeure, 0.19.26) 
just an aspect of the film's cinematography, the framing of each shot, but is also a key to understanding the conflict between the characters and their struggles. The concept of frame in this second regard connects to a more general definition of framing as a process of interpretation and of frame as an interpretative context. It might be argued that the film depicts an identity crisis within the family, following the avalanche scene, and that this crisis stems from the characters' inability to attribute meaning to Tomas's actions during the event or to relate their experience to the family as a narrative construct. "Stories that become incorporated in the family history and communicate important information about the family involve a shared frame," write Kiser et al., and the idea of a shared frame in this regard is connected to the internalized models and schemas commonly applied in theories of communication and social theory. ${ }^{3}$ Frames and frameworks of different kinds are said to make us attribute meaning to experience, and they refer to our ways of making sense of the world. "Families use this shared frame to coconstruct coherent stories," writes Kiser et al., and it is interesting to note that the family in Force Majeure exemplifies how traumatic experience "can derail family storytelling." 4 It becomes clear that one of the problems that the parents in the family are confronted with after the averted disaster is how to make sense of their experience and to coconstruct a coherent shared story. This hermeneutical crisis is especially visible through the struggles of the character Ebba. She has a key function, which is also acknowledges by Jakob Lothe, as the character driving the plot and the conflict between her and Tomas forward. 5

After the avalanche scene, a silence prevails between the family members, an inability to speak about what has happened. During a dinner with another couple staying at the hotel, when asked about their day, Tomas states that they "had some kind of an experience actually" and then he relates the story of their afternoon (00:25:00). ${ }^{6}$ Ebba reacts to his version and corrects him, explaining that he ran out on his wife and children, taking only his gloves and iPhone with him. Tomas and Ebba start arguing in front of the other couple. After the dinner, they have a private conversation about the events of the day and Ebba states that it is strange that Tomas will not confess to what has happened. $\mathrm{He}$ gets mad, stating that they have different versions of what actually happened. In their conversation, Ebba emphasizes the importance of a shared view. This shared view of the event is argued to be important for the children and for themselves. In other words, for the family as a whole. 
In their dialogue, it becomes clear that a shared view and a common experience can only be achieved though storytelling, that the experience needs the shape of a narrative. "There was an avalanche," states Ebba, "we were frightened, but everything went fine" (00:31:50). This "minimal narrative" is supposed to formulate a shared view and Tomas, who is not depicted as the villain in this scenario, quickly agrees to this version. "I'm totally okay with that," he says and shakes Ebba hand, as if the argument was a business transaction (00:31:54). Of course, Ebba's minimal narrative is not persuasive enough to hold a common experience or erase the fact of what happened - Tomas leaving his family in the face of a catastrophe. Therefore, Ebba becomes more and more troubled by her inability to make sense of the experience within the formerly shared family frame. The silence returns between Ebba and Tomas. She goes skiing on her own, without her husband and the children. Yet, when Tomas's friend Mats and his girlfriend Fanny arrives at the hotel, a new situation, similar to the dinner with the other couple, arises and Ebba get drunk and once again tells the story of what happened to them during the avalanche. Tomas act of cowardice is related and then examined between the two couples. When he continues to deny Ebba's version, his wife urges them to watch the film of the event on Tomas's phone. Faced with the evidence, he agrees that it might look as if he was running, but he is not prepared to confess to what he and the others now know to have happened.

Tomas eventually breaks down, or at least feigns a breakdown in which he confesses to all his faults as a man, lying, cheating, and so on. He speaks about himself in the third person as if he is speaking about someone else. The whole scene that follows in the hotel room plays out like a scene from a play, something that Tomas directs and where he and the children are made to play their roles, as a remorseful husband and as concerned children, wanting to recreate the lost unity of the family. Ebba resists, but is pulled by her daughter Vera into a group-hug on the floor, and for the first time since the avalanche the family is framed together again as a unity in this symbolic family portrait, reminiscent of the portraits at the beginning of the film. That the shot does not represent a reconciliation is apparent from Ebba's refusal to play her part. There is something wrong with the picture. In comparison to the family portrait in the beginning, where the family members stand next to each other and the internal hierarchy within the family is stable, in this shot Tomas lies on the floor while Ebba resists her place at the top of the family hierarchy. 
The sequence that follows, during "The Last Ski Day," sheds further light on the characters' need to restore the family frame. On their last day of skiing, it is Ebba's turn to stage a scene, which has the function of restoring the order within the family and between husband and wife. She decides to stage a fake accident in which Tomas can save her. She casts her husband in the role of the hero instead of the role of coward or villain. Ebba gets lost in the fog and cries for help. Tomas takes off his skis and runs, once again in his ski boots, yet this time toward the supposed accident. He returns triumphantly, carrying Ebba. The family is reunited, happy and embracing, framed as a unity that corresponds to the preconceived image of the nuclear family, as represented already in the first shot of the film.

The function of this scene is then to restore the order within the family, to reestablish the shared frame of the family, the familiar ways of making sense of themselves in relation to the world around them. The viewer, however, is once again made aware of the artifice of these actions, the symbolic nature of the scene. Just as in the introductory portrait in the film, the constructedness of this family portrait is flaunted through irony. The viewer is made aware that the family is in the process of staging a picture. As the first shot of the film is disrupted by the presence of the tourist photographer, here Östlund makes use of the temporality of the scene and lets the shot continue after the action is over. Instead of cutting when the audience expects, when the family is reunited and happy, the shot includes what happens afterwards, when the rescue scene is over. The musical score disappears and the characters are unsure how to act now that the scene they have acted out is over. Ebba rises and states laconically: "Good" (01:48:58). Tomas asks if she needs help and his wife answers that she is fine. She starts to walk up the hill in order to fetch her skis from where Tomas supposedly "rescued" her. He and the children stay behind. Given how the scene ends, it is clear that Ebba never was in danger. It is as if the viewer gets as glimpse behind the scenes, thus being made conscious of the constructed nature of this scene and the family it supposedly reunites.

\section{CAMERA AND NATURE: OUTSIDE THE FAMILY FRAME}

In the previous section, I have traced the notion of framing in relation to the characters', especially Ebba's, struggles to makes sense of their experiences after the avalanche. As I have discussed, framing in Force Majeure is a technical as well as a thematic matter. Framing in regards to cinematography is always a matter of limitation and 
exclusion: "Every shot is demarcated by the frame: who or what fits in the image, and who or what falls outside of it." 7 This idea of framing as limitation and exclusion applies equally to the notion of framing in the thematic sense, as a matter of how the family in the film is in need of a shared frame and how this frame is based on inclusion and exclusion. In this section, I therefore intend to reflect upon aspects of framing in connection with the film's visual aesthetics and how the camera takes on a role of its own in Force Majeure.

If we return to the opening scene, we are, as discussed previously, made conscious from the very outset that we are watching a family acting "like a family," that is, according to prevailing stereotypes and norms surrounding the nuclear family, and in front of an audience. This is underlined by the appearance of screens in the film and the fact that Ebba and Tomas often argue and discuss in front of audiences, such as other couples, the children, or the cleaner who is often present during their "private" discussions outside the hotel room. The film does not, it becomes more and more evident, depict the private, intimate, idiosyncratic struggles of a particular married couple, but rather depicts the family as a representation, and the struggle concerns how to sustain this representation. In this regard, it becomes necessary to establish a distance towards the characters.

Östlund's films, especially his first three films, are often associated with a "fixed camera position resulting in detached objective perspectives" and "long, drawn-out scenes that emerge slowly in the cinematic environment," as described by Ursula Lindqvist. ${ }^{8}$ Although Force Majeure can be regarded as a departure from his earlier films, based on the use of shifting camera positions and different uses of framing and cutting, the detached objective perspective characteristic of Östlund's visual aesthetics can be found in several key scenes in the film. In the avalanche scene, for instance, the camera is placed at a distance from the characters creating a long shot. We see them together at the table in the outdoors seating of the restaurant, and on the soundtrack we hear their voices. There are no cuts in this static shot, which lasts approximately three and a half minutes.

The scene begins as another family portrait, where nature provides an idyllic backdrop. When the avalanche is triggered, the idyll is disrupted and it is as if the image of the family and nature itself falls apart in front of us. The duration of the scene is important because it shows how the beautiful composition, reminiscent of commercial images in travel magazines, is transformed. The tranquil image erupts into chaos and the role of the camera is to 
show what is being excluded, in the same way as the rescue-scene towards the end includes how the characters act after the action of the scene has ended. Even before the avalanche scene, the family portraits appearing during the "First Ski-Day" often include a form of disturbance in order to disrupt the family frame. When the family lies in bed together dressed in the same clothes, resting after skiing all day, Tomas's phone rings. The scenes begin as belonging to a stereotypical family album and then the frame includes what is otherwise excluded from the family portraits. With the use of the long static shots, the camera is given the role to register and make the viewer see what the characters themselves are unable, or unwilling, to perceive. The static framing of these shots, and the use of long takes without cuts, seems to present an objective reality outside the fiction of the nuclear family that the characters are living.

As discussed, Tomas's act of cowardice cannot be incorporated into the ongoing narrative about the family or made sense of within existing frameworks. The static long shot of the avalanche presents a camera position from which the viewer can watch objectively what happens. Despite the mist from the snow, we see Tomas running away and then returning to his family. Later in the film, the iPhone images of the event that the characters watch together confirms what we as viewers already know, and what Ebba and Tomas know to have happened. Therefore, there is never any doubt for the viewer about what happened during the avalanche or which version of the event is true. The focus is instead, as I have shown, on the impossibility to deal with or make sense of Tomas's action within the framework in which the family defines itself and according to how he perceives himself within the family. Everything that does not fit within his self-image is excluded, and he speaks of himself in the third person when he confesses to "his" faults, that is, the faults of the other Tomas, the internal villain.

In the movie, Tomas's actions are connected to an inescapable nature or to impulses that he cannot control. As Tomas says to Ebba, "I am a victim too," meaning that he is a victim of natural forces that he cannot control - his own instincts (01:35:27). Mats explains his friend's behaviour as a natural instinct to survive, and he refers to this instinct as a force inside us all - an "urkraft". Ebba states that her natural direction is towards her children, while Tomas's natural direction is away from his family. In Force Majeure, external nature is controlled and commercialized in the form of the ski resort. Even the avalanche, although it appears threatening, is a controlled avalanche, triggered by explosives. This constructed and controlled nature is thus used in the film as a contrast to the 
inability to control impulses and natural instincts. What disrupts the socially constructed order within the family, the film seems to argue, is in fact the natural impulses and instincts inside man that cannot be controlled. What the avalanche triggers is a reaction that is at odds with the idea of what the characters take to be natural. The role of the camera is crucial in this regard because its objective perspective can include what is normally excluded from within the family frame. We are confronted by nature in this scene, a nature that escapes the characters' attempts at control, yet is registered by the objective camera. The camera sees through the social constructions, the images of the family, and the representations of nature. It is notable that running away from his family is the most "natural" thing that Tomas does in the whole movie. As argued, his break-down later on in the film is a performance, and even his crying is triggered by his own desire to create a reaction, to stage a scene. It is, in a sense, a controlled avalanche. During his day of skiing with Mats, he is urged by his friend to purge himself of anxiety through a primal scream on top of a mountain. Once again, Tomas attempts to control his inner nature, the impulses that he cannot control - his "urkraft". Running away in the face of danger seems in fact to be the only time in the film that he is not acting.

\section{THE MOVEMENT OF COMEDY AND THE SENSE OF AN ENDING}

As argued in this essay, the film's basic structure adheres to a conventional form of narrative progression. It moves from a conflict or a disruption of order to the resolution of the conflict and a restoration of order. Yet, as we have seen, Force Majeure also flaunts this structure by making the viewer aware of how the characters - especially Ebba, as the one who is driving the conflict forward - are forced towards a predictable solution, a restoration of order according to established conventions. The film thus makes use of a conventional structure of narrative progression while at the same time undermining its effects. The scene towards the end when Tomas rescues Ebba does not work as a conclusion, although we can identify it as a motif of the-hero-rescuing-a-women-in-danger. In this regard, we can consider Force Majeure to be a parody. However, the film does not end here and it would be limiting to view the film as just a parody of conventional storytelling and how these conventions are reproduced within the stories families tell about themselves. The actual ending of the film moves away from parody towards a different resolution. 
After the scene of mock-heroism on the foggy ski slope, we see the family leaving the hotel. They walk through a tunnel towards the camera and the camera zooms in on them. They walk side-by-side, together as a family again, and the shot ends just before they are out of the frame. The last sequence of the film depicts the bus ride from the ski resort along the snaking, narrow road. The main characters as well as the secondary characters are present on the bus, which is driven by an incompetent bus driver who is unable to smoothly or safely take the passengers down from the mountain. The driver has problems driving the bus through the curves, and it is clear that he is not sure how to operate the large vehicle. The passengers get nervous and scared. Ebba gets more and more upset, and finally she screams at the driver to stop the bus and let her out. He does as she commands, and when Ebba leaves the rest of the passengers follow. Everyone leaves the bus, except Charlotte, Ebba's confidant from the hotel, who alone stays when the bus drives on, leaving the passengers on the road. They begin to walk and in the last scene of the film, we see them all together on the road. The camera is moving in front of them, along with them. Tomas is offered a cigarette, declines, then regrets his decision and accepts the lit cigarette. His son Harry ask if he smokes, and he confirms that he does. There is no musical score until the final seconds of the film. We hear footsteps and voices. The music slowly builds and we do not recognize the score from earlier in the film. Instead of the recurring score, a fast and frenetic performance of a bit from Vivaldi's "Four Seasons: Summer" on accordion, we hear slow ambient music, with an organ giving the shot an almost sacred atmosphere.

The question, then, is how to interpret the final sequence in the film. In most discussions on Force Majeure, the focus is on Ebba's reaction in the bus and how her fear and behaviour is connected to Tomas's act of cowardice earlier in the film. Although the scene in the bus is not identical to the avalanche-scene, and the threat of the bus driver does not equal the threat of the avalanche, it is now Ebba's turn to react impulsively, without thinking of the consequences. Jakob Lothe perceives the ending to be reconciling and even optimistic because Tomas does not criticize Ebba's behaviour. ${ }^{9}$ Christian Gullette argues that the ending "predictably returns to traditional hierarchies", but also asks if it might be a way for Östlund to "do away with normative categories of femininity" by letting Ebba be impulsive and scared instead of strong and resilient. ${ }^{10}$ In connection with my discussion on framing, the most interesting aspect of the ending is that it frames a large group of people within which the nuclear family is finally dissolved. To 


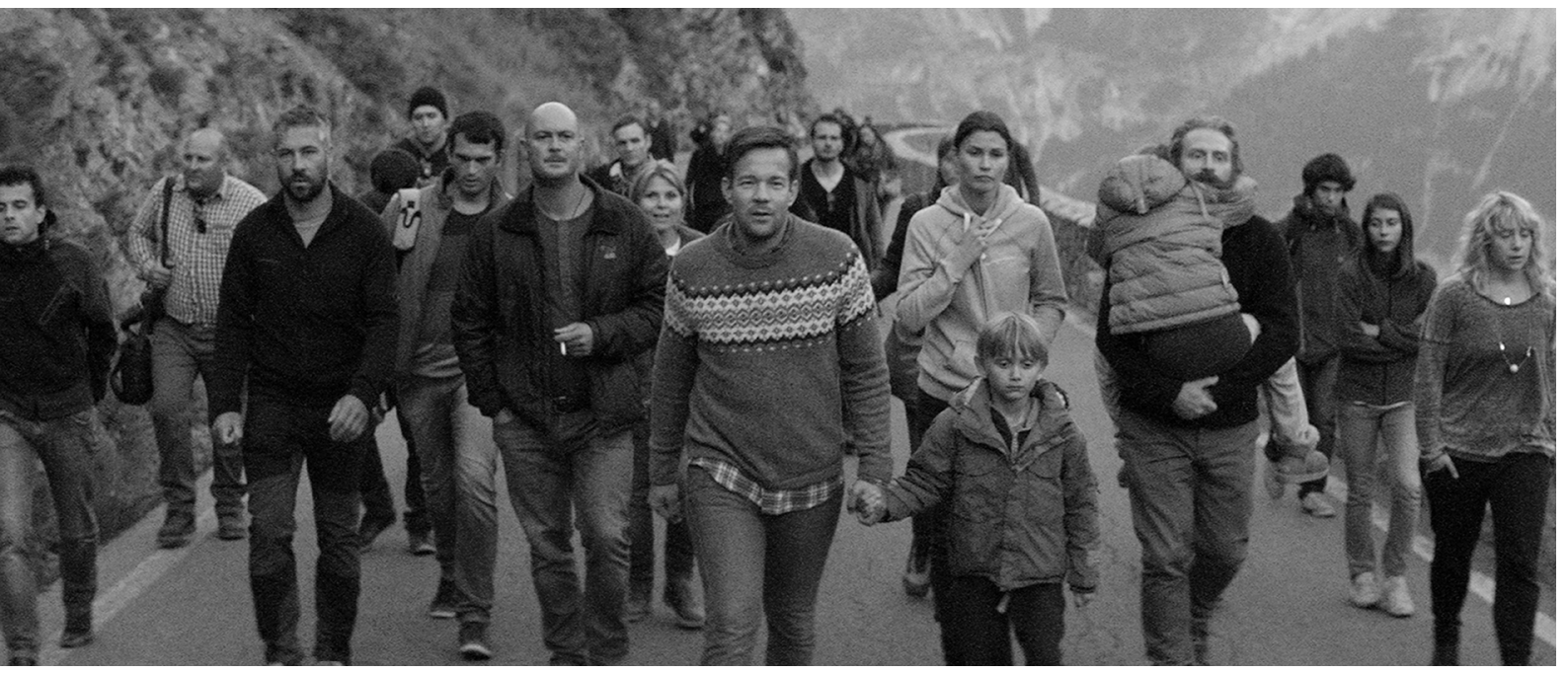

(Force Majeure, 1.57.24) 
interpret this final shot, I argue, we need to see it in relation to the rest of the film and its concern with family framing.

It is not just Ebba's reaction that can be connected to earlier scenes. The very composition of the final shot invites us to see the image in relation to the family portrait at the beginning of the film and to the scenes that precede the bus ride. The final shot can be contrasted with the first shot of the film in order to indicate that it has depicted a movement from the enclosed, limited family frame to a collective image where the family members are a part of a larger community. The irony and self-conscious parody that has characterized the film is no longer present and, as mentioned above, the music indicates a departure from the rest of the film. Likewise, it is notable that the camera, often static in the film or moving towards the characters in zooms of different speed, is now moving along with the people in a slow dolly shot keeping the pace with the walking crowd.

For these reasons, it is possible to view the final shot as another "family portrait," yet one in which the very notion of "family" is redefined. By juxtaposing this shot with earlier shots of the family members in the film, it is clear that the final scene is not a departure from the narrative progression of the film, but rather its completion. The crisis in the family and the inability to restore what has been broken actually opens a possibility for something else, something different. By rescuing Ebba on the ski slope, Tomas has not changed anything or erased what has happened. By letting him "save” her, Ebba has only made a symbolic gesture in which she sacrifices herself in order to restore the order in the family that has been disrupted. The progression of the film moves, as stated, from the disruption of order to the restoration of order, yet by undermining this structure, the effects of closure are omitted. Instead of establishing a status quo within the family, the final scene forces them towards something outside the family frame. The family portrait of the beginning of the film cannot be restored, and the ending of the film acknowledges that they now understand or are beginning to understand that they cannot simply rely on their previously shared frame as a family.

In the last scene, the family members no longer walk together side-by-side. Instead, Ebba walks behind Tomas, and when Vera gets tired, Ebba asks Mats to carry her daughter. Although it is a small gesture, it changes the relation within the family in the final frame. When Tomas accepts the cigarette, offered by a stranger in the group, Harrys asks if he smokes and the fact that he does something out-of-character in the eyes of his family also indicates 
that the frame has changed. While the act of smoking a cigarette might seem to be a stereotypical macho act, it is depicted as a small, comic gesture that shows how Tomas realizes that he does not have to act out his usual role anymore. It is notable that he first declines the offer of a cigarette and then accepts it: "Actually, can I take one?" (01:59:39)

While being a departure from self-conscious parody, it would be misleading to argue that the end is "serious" while the rest of the film is dominated by an ironic mode. This might imply that the end is not integrated with the rest of the film. The final shot is, as I argue, a continuation in relation to the narrative progression of the film, and it might be regarded as its coda. Perceived in this way, it becomes interesting to note how Force Majeure relates historically to certain comedic traditions. In Northrop Frye's seminal discussion on the genre of dramatic comedy, he discussed how "the movement of comedy" can be understood as "the movement from one kind of society to another", and by looking at the final shot of Force Majeure, it is possible to make a connection between the film and the comedic traditions described by Frye. ${ }^{11}$ Comedy is, according to Frye, designed to "ridicule lack of self-knowledge" and is populated with humours, "people who do not fully know what they are doing, who are slaves to a predictable self-imposed pattern of behaviour." 12 This description fits Force Majeure well, and we can identify many humours in the film, whether Tomas and Ebba, or Mats and Fanny, all of whom are slaves to a predictable self-imposed pattern of behaviour. However, it is not my intention to argue that Force Majeure answers to a generic model of dramatic comedy going back to the New Comedy of antiquity. Rather, I simply intend to note how certain elements, that Frye describes as belonging to the comedic tradition stemming from the Greek New Comedy, can in fact be illuminating in order to explicate the function and potential of the ending of the film, especially its final "movement."

"The tendency of comedy is to include as many people as possible in its final society," writes Frye, who discusses why comedies often end with some kind of party or festive ritual, for example a wedding or banquet. ${ }^{13}$ Frye explains that in the last scene the comedic dramatist "usually tries to get all his characters on the stage at once" so that the audience "witnesses the birth of a renewed sense of social integration": "Thus a new social unit is formed on the stage, and the moment that this social unit crystallizes is the moment of the comic resolution." 14 Comedy is usually dependent on its movement towards a "happy ending", and it might seem 
strange to regard the slow and gloomy ending of Force Majeure as "happy", yet in the sense that Frye explains it can been seen as a comic resolution to the narrative progression of the film. Likewise, it might seem far-fetched to argue that the crowd walking along the road at the end of Force Majeure exemplifies the movement of comedy, because the shot does not tell us anything about what is to come, yet according to Frye the ideals of the emerging society or social unit at the end of comedy are seldom defined or formulated. For the same reason, the main character (the hero in comedies) is often "left undeveloped" because "his real life begins at the end of the play, and we have to believe him to be potentially a more interesting character than he appears to be."15 This description might suit Tomas, who walks at the centre of the final shot as if he is the hero of the film, still undeveloped, but all the characters are together now and the film ends with the possibility of change, rather than actual change - the emergence of a new social unit, not a formed society. They are all in fact "undeveloped". The ending of the film can also be seen as an "invitation to the audience to form part of the comic society" because, as Frye acknowledges, the resolution of comedy also comes from the audience's side. ${ }^{16}$ It is notable that in the final shot, the crowd is walking towards the camera, and the camera is moving along with them, creating a different viewer position than the one established in the opening shots of the film and confirmed by the static camera position in several of the key scenes in the film. The ironic distance is replaced by an invitation to take part in the formation of a new social unit, not yet defined or formulated. The crowd is walking towards us, confronting us, and then the film ends.

The images from Ruben Östlund's films are reproduced with permission and assistance of Plattform Produktion. 
1 Marianne Hirsch, Family Frames: Photography, Narrative, and Postmemory (Cambridge, Mass: Harvard University Press, 1997), 7.

2 Ibid., 7.

3 Laurel J. Kiser, Barbara Baumgardner, and Joyce Dorado. "Who Are We, but For the Stories We Tell: Family Stories and Healing," Psychological Trauma: Theory, Research, and Practice. 2(3) 2010, 246.

4 Ibid., 247.

5 Jakob Lothe, Etikk i litteratur og film (Oslo: Pax 2016), 225.

6 Force Majeure, directed by Ruben Östlund, Plattform produktion, 2014.

7 Peter Verstraten, Film Narratology, trans. Stefan van der Lecq (Toronto: University of Toronto Press, 2009), 70.

8 Ursula Lindqvist, "The Art of Not Telling Stories in Nordic Fiction Films," A Companion to Nordic Cinema, ed. by Mette Hjort and Ursula Lindqvist (Malden, Ma.: Wiley Blackwell 2016), 549.

9 Lothe, 226.

10 Christian Gullette, Challenging Swedishness: Intersections of Neoliberalism, Race, and Queerness in the Works of Jonas Hassen Khemiri and Ruben Östlund, (PhD diss., University of California, Berkeley), 67.

11 Northrop Frye, Anatomy of Criticism: Four Essays, (Princeton: Princeton University Press [1957] 2000), 163.

12 Northrop Frye, "The Argument of Comedy," Shakespeare: An Anthology of Criticism and Theory 1945-2000, ed. by Russ McDonald (Malden, MA: Blackwell Pub. 2007), 94.

13 Frye, Anatomy of Criticism: Four Essays, 165.

14 Frye, "The Argument of Comedy", 94.

15 Frye, Anatomy of Criticism: Four Essays, 169.

16 Ibid., 164. 